\title{
Botulismo canino: Revisão
}

\author{
Elissandra da Silveira1 \& Sandra Márcia Tietz Marques $^{2 *}$ \\ ${ }^{1}$ Médica Veterinária, Residente Hospital de Clínicas Veterinárias, Faculdade de Veterinária, Universidade Federal de Rio grande do Sul \\ (UFRGS), Porto Alegre, RS, Brasil. \\ ${ }^{2}$ Médica Veterinária, Dra., Departamento de Patologia Clínica Veterinária, Faculdade de Veterinária, Universidade Federal de Rio grande \\ do Sul (UFRGS), Porto Alegre, RS, Brasil. \\ *Autor para correspondência: smtmuni@hotmail.com
}

RESUMO. O botulismo tem como agente causal Clostridium botulinum, bacilo gram positivo anaeróbico obrigatório, formador de endosporos, encontrado no solo e em muitos sedimentos de água fresca. É uma afecção neuroparalítica, sendo descritas sete neurotoxinas ( $\mathrm{A}$ a $\mathrm{G}$ ), sendo a $\mathrm{C}$ mais comumente encontrada em pequenos animais. Em cães, o alimento geralmente está contaminado com a neurotoxina do tipo $\mathrm{C}$, causando bloqueio da acetilcolina nos receptores da junção neuromuscular, geralmente de horas a dias após a ingestão, causando paralisia de neurônio motor inferior, com fraqueza rápida progredindo para decúbito. O objetivo desse trabalho é uma atualização do botulismo canino, como diagnóstico primário ou diferencial em diagnóstico neurológico, abordando desde sua etiologia, incidência, patogenia, manifestações clínicas, tratamento e prognóstico.

Palavras chave: Clostridium botulinum, cão, neurotoxina

\section{Botulism canine: Review}

\begin{abstract}
Botulism, described the first time in the nineteenth century, it is the causative agent Clostridium botulinum, bacillus gram positive anaerobic mandatory, endospores maker, found in soil and in many freshwater sediments. It is a neuroparalytic affection being described seven neurotoxins (A to G), the $\mathrm{C}$ most commonly found in small animals. In dogs, food is generally contaminated with neurotoxin type $\mathrm{C}$ causing blockade of acetylcholine receptors at neuromuscular junction, generally from hours to days after ingestion, causing lower motor neuron paralysis with fast weakness progressing to recumbence. The aim of this study is an update of canine botulism, as primary diagnosis or differential diagnosis in neurological, addressing since its etiology, incidence, pathogenesis, clinical manifestations, treatment and prognosis.
\end{abstract}

Keywords: Clostridium botulinum, dog, neurotoxin

\section{Introdução}

Botulismo tem por agente etiológico Clostridium botulinum, bacilo anaeróbico, gram positivo, formador de endósporos que sintetizam neurotoxina. É uma doença neuroparalítica causada por sete neurotoxinas (A a G). Clostridium botulinum tipo $\mathrm{C}$ causa a maioria dos surtos dos animais domésticos (Bruchim et al., 2006; Coleman, 1998; Quinn et al., 2005). O botulismo foi descrito pela primeira vez como doença clínica no século XIX. Em humanos, o botulismo é causado principalmente pelos sorotipos A, B e E, e raramente pelo sorotipo F (Sobel et al., 2004).
O botulismo animal causado pelo grupo III produz toxina tipo $\mathrm{C}$ e $\mathrm{D}$, ou outras formas quiméricas $\mathrm{C} / \mathrm{D}$ e $\mathrm{D} / \mathrm{C}$, com 17 isolados caracterizados e sequenciados. É considerada doença emergente na Europa, notadamente na produção avícola, na qual os genomas identificados podem ter plasticidade e capacidade para se adaptarem e evoluírem em novos ambientes (Woudstra et al., 2016).

O botulismo pode surgir a partir da ingestão de toxina pré-formada, infecção da ferida ou toxi infecção intestinal. Todas as três formas podem ocorrer em humanos bem como em animais. $\mathrm{O}$ 
exame de botulismo na prática veterinária pode alertar os médicos para os perigos que podem ocorrer com a introdução de alterações dietéticas e vedação hermética dos gêneros alimentícios. Há também a possibilidade de que o desenvolvimento de pica devido à falta de nutrientes essenciais pode levar à ingestão de substâncias contaminadas com a toxina botulínica (Critchley, 1991).

Os animais ingerem a toxina pré-formada, contida em restos de carcaças em putrefação, vegetação em decomposição e alimentos enlatados contaminados. Uma vez absorvida, especialmente na região proximal do intestino delgado, a toxina se liga de maneira irreversível na membrana pré-sináptica da junção neuromuscular, impedindo liberação de acetilcolina, ficando a sinapse lesada do ponto de vista funcional (Lorenz \& Kornegay, 2006).

O objetivo desse trabalho é uma atualização sobre o tema de botulismo canino, uma das afecções da junção neuromuscular, importante como diagnóstico primário ou diferencial em diagnósticos neurológicos, abordando desde sua etiologia, incidência, patogenia, manifestações clínicas, diagnóstico, tratamento e prognóstico.

\section{Etioepidemiologia}

Clostridium botulinum é um bacilo gram positivo e anaeróbico, que apresenta esporos ovais subterminais, cujo habitat natural é o solo, poeira, sedimentos marinhos, agroprodutos frescos e industrializados. A espécie produz sete tipos antigênicos de toxina botulínica designados de A a G, sendo o botulismo canino mais comumente causado por $C$. botulinum tipo $\mathrm{C}$, porém há relatos do tipo $\mathrm{A}$ e $\mathrm{E}$ em canídeos (Myllykoski et al., 2011). A resistência térmica dos esporos varia de acordo com o tipo de toxina e cepa, sendo o calor úmido a $120^{\circ}$ por cinco minutos letal, assim como aquecimento a $80^{\circ} \mathrm{C}$ por 20 minutos (Nelson \& Couto, 2015).

Os reservatórios da bactéria estão no solo e sedimentos aquáticos. Veículos de intoxicação são materiais animais e vegetais contaminados, os esporos germinam e produzem toxina, que é ingerida por animais necrófagos ou contaminam o ambiente. Detritos domiciliares em deterioração também pode ser fonte de contaminação.

\section{Incidência}

Em 1978 foi descrito o primeiro caso de botulismo canino, causado por Clostridium botulinum tipo $\mathrm{C}$ em cães Foxhounds na Geórgia (Lorenz \& Kornegay, 2006). Um cão australiano filhote, macho, apresentou severa e difusa paralisia do neurônio motor depois de ter devorado o corpo de um pato apodrecendo em um parque em Sydney, Austrália. Dois outros cães que comeram porções menores da mesma carcaça foram afetados, porém sem gravidade. A toxina de $C$. botulinum tipo $\mathrm{C}$ foi isolada a partir das fezes do cão severamente afetado. Entretanto, o soro continha 25 DL50 de toxina $/ \mathrm{mL}$. A alta contagem de toxina botulínica nas fezes diminuiu progressivamente durante as semanas que se seguiram, mas 114 dias após a ingestão da carcaça, a toxina ainda estava presente nas fezes (Farrow et al., 1983).

Durante um surto de suspeita de botulismo em aves aquáticas no lago Hamilton (Arkansas, EUA) um cão foi internado em uma clínica veterinária com disfunção de neurônio motor inferior, característica parcial de botulismo. O tratamento consistiu de antibióticos e terapia de suporte intensivo, porém, devido a complicações o animal veio à óbito. A análise de uma amostra de soro obtida antes da morte confirmou a presença de toxina botulínica tipo C (Wallace \& McDowell, 1986).

Três casos de cães que apresentaram sintomas de doença do neurônio motor inferior agudo são relatados, nos quais o diagnóstico de botulismo tipo C foi estabelecido. Em um dos cães, botulismo foi creditado pela ingestão de carcaças de aves, contendo a toxina tipo C; nos outros dois casos, a relação causal com aves foi extremamente sugestiva. A toxina estava presente no soro nos dias um e três; Clostridium botulinum ainda estava presente nas culturas das fezes dezesseis dias após o início dos sintomas (Tjalsma, 1990). No Senegal foram relatados casos de dois cães portadores da toxina do tipo $\mathrm{D}$ (Barsanti, 2011; Doutre, 1983).

Os casos de botulismo são raros e casos durante o período gestacional são ainda mais raros. Durante a gestação, a doença, bem como o tratamento pode causar aborto ou malformação do feto. $\mathrm{O}$ metronidazol foi utilizado neste trabalho, mas não é recomendado durante a gestação, especialmente durante as primeiras tres semanas, um efeito teratogénico tem sido 
demonstrado em animais de laboratório (Johnston et al., 2001).

Uma cadela de dois anos de idade e gestante apresentou um quadro agudo de tetraparesia flácida e desconforto respiratório. O exame neurológico revelou disfunção difusa do neurônio motor e a neurotoxina $\mathrm{B}$ de $C$. botulinum foi isolado a partir do soro do cão. $O$ animal foi internado e recebeu tratamento de suporte e a recuperação foi completa dentro de um mês e parto ocorreu sem complicações 49 dias após a admissão, com os filhotes sem quaisquer defeitos congênitos. A suspeita da fonte de contaminação recaiu sobre a incorreta conservação do alimento seco (Lamoureux et al., 2015).

\section{Patogenia e manifestações clínicas}

A toxina ingerida é absorvida a partir da mucosa glandular do estômago e intestino delgado (jejuno) fazendo toxemia, sendo a fonte mais comum pela ingestão de carcaça (Simpson, 2013). Há relatos de infecção de feridas (Lorenz \& Kornegay, 2006) ou por inalação de partículas de poeira contaminados (Devers \& Nine, 2010). Age especificamente sobre o sistema nervoso periférico, impedindo a transmissão dos impulsos das terminações nervosas para os músculos (Rossetto et al., 2013). Ocorre ligação da toxina aos receptores, entrando por endocitose nas células nervosas e as vesículas contendo a toxina permanecem na junção mioneural, interferindo na liberação de acetilcolina a partir das placas finais em neurônios motores, resultando em falha na transmissão neuromuscular (Chrisman et al., 2005).

Os sinais clínicos variam de acordo com o período de incubação, que pode ocorrer em poucas horas a vários dias. Os cães mostram fraqueza simétrica progressiva, que acomete os membros pélvicos e progride para os membros torácicos, se instalando rapidamente um quadro de tetraparesia flácida, com hiporreflexia ou arreflexia e hipotonia muscular, dificuldade de deglutição, afonia, diminuição do reflexo palpebral, sendo a gravidade das manifestações clínicas dependente da quantidade de toxina ingerida. $\mathrm{O}$ acometimento da musculatura respiratória pode levar o animal à óbito. $\mathrm{O}$ curso habitual da afecção é de menos de 14 dias. Observa-se frequentemente paralisia facial, disfonia, disfagia e megaesôfago decorrente do envolvimento do nervo craniano, constipação e retenção urinária. Pode ocorrer paresia e depois, paralisia de músculos intercostais e diafragma, de modo que a respiração deve ser monitorada para detectar hipo ventilação e hipóxia (Chrisman et al., 2005). A paralisia dos músculos respiratórios leva à respiração abdominal, temperatura corporal permanece normal e animais afetados ficam alerta (Quinn et al., 2005).

\section{Diagnóstico}

O diagnóstico se baseia em histórico de ingestão de carcaça e achados do exame clínico (Nelson \& Couto, 2015). A confirmação do diagnóstico não é mais realizada pela inoculação intraperitoneal de camundongos com amostras de soro, fezes ou vômito do paciente suspeito, porque está em desacordo com os comitês de ética vigentes (Tortora et al., 2009). A identificação de toxinas mediante exame de ELISA gera uma alta porcentagem de falsos negativos. Métodos como Radio imunoensaio (RIE) e Reação em Cadeia da Polimerase (PCR) não são alternativas diagnósticas práticas (Lorenz \& Kornegay, 2006).

O diagnóstico definitivo de botulismo é difícil, pois os níveis circulantes de toxina geralmente são baixos, o material fonte de infecção pode não estar disponível e os métodos analíticos disponíveis não têm boa sensibilidade (Uriarte et al., 2010). Amostras de soro pareadas coletadas por três semanas são importantes para demonstrar o incremento do título de anticorpo (Bruchim et al., 2006); e é sugerido como método de diagnóstico como nos casos de botulismo em cavalos (Whitlock \& Buckley, 1997), em bovinos (Gregory et al., 1996; Jubb et al., 1993) e em aves silvestres (Rocke et al., 1998).

É de suma importância atentar para diagnósticos diferenciais, em especial raiva, polirradiculoneurite aguda, paralisia por carrapatos e miastenia grave. Deve ser levado em consideração a polirradiculoneurite aguda, onde algumas evidências têm sugerido o envolvimento de organismos de clostrídios no intestino como fonte dos antígenos que são aparentemente semelhantes às proteínas que constituem parte das raízes nervosas ventrais e dos nervos motores. Os animais apresentam tetraparesia flácida progressiva e aguda (Chrisman et al., 2005). A paralisia por carrapatos é resultado da liberação da acetilcolina na junção neuromuscular ou prejuízo da despolarização dos neurônios motores inferiores distais, devido à secreção de uma neurotoxina pelos carrapatos 
dos gêneros Ixodes e Dermacentor durante o repasto sanguíneo (Chrisman et al., 2005). A miastenia greve se apresenta como fraqueza episódica ou induzida por exercícios decorrentes do comprometimento da transmissão da acetilcolina nas junções neuromusculares dos músculos esqueléticos.

\section{Tratamento e prognóstico}

Não há tratamento específico para o botulismo, sendo baseado somente em medidas de suporte (Nelson \& Couto, 2015). O antimicrobiano não tem utilidade, pois se trata de uma toxina pré-formada (Tortora et al., 2009). Há soro anti-botulínico para a venda comercial; no cão devem ser empregados produtos que contenham anticorpo tipo $\mathrm{C}$, o mais rápido possível, pois este é capaz de neutralizar a toxina quando esta não está ligada a receptores présinápticos. É aconselhada a aplicação prévia por via subcutânea de $0,1 \mathrm{~mL}$ de soro para avaliar eventual reação de hipersensibilidade. Se não ocorrer reação em 20 minutos, pode ser administrado a dose completa e repetir a dose 4 horas após a primeira aplicação (Fernández \& Bernardini, 2010).

Se a ingestão recente está sob suspeita, esvaziamento gástrico e lavagens são úteis. Laxantes e enemas podem auxiliar na remoção da toxina não absorvida. Agentes terapêuticos como a tetraetilamida e o hidrocloridrato de guanidina melhoram a liberação dos neurotransmissores na junção neuromuscular e podem ser eficazes quando administrados por via endovenosa (Quinn et al., 2005).

Cuidados de enfermagem relevantes são: manter o paciente em local acolchoado, trocas de decúbito, monitoramento de tosse e desconforto respiratório; executar compressão vesical a cada 6 horas se o paciente for incapaz de urinar, edemas e laxante caso necessário; uso de colírios de lágrimas artificiais ou pomadas lubrificantes oftálmicas em caso de reflexo palpebral ausente; alimentar em decúbito external ou uso de sonda esofágica, fisioterapia, acupuntura, banhos de turbilhonamento ou natação; estímulo a ficar em pé e sustentar o corpo, caminhadas com tipóia.

A eficácia do uso de antimicrobianos não foi comprovada (Lorenz \& Kornegay, 2006) e geralmente não é indicado, a menos que haja infecção intercorrente (Chrisman et al., 2005). A terapia com penicilina e metronidazol parece ser questionada, uma vez que a lise de Clostridium botulinumno intestino poderia aumentar a disponibilidade da toxina (Ferreira \& Domingues, 2008). A recuperação requer que as terminações nervosas se regenerem, logo ocorre lentamente. Muitos cães afetados se recuperam completamente em duas a três semanas.

O prognóstico é favorável se o paciente não desenvolve um quadro rápido e progressivo. Os casos brandos podem se recuperar sem tratamento.

Como método preventivo eficaz evitar ingestão de alimentos crus ou deteriorados por parte dos animais de companhia. Em pequenos animais não há disponível comercialmente vacina com toxina de $C$. botulinum tipo $\mathrm{C}$, logo esse tipo de imunização deve ser alvo de pesquisas. $O$ exame de botulismo na prática veterinária pode alertar os médicos para os perigos que podem ocorrer com a introdução de alterações dietéticas e vedação hermética dos gêneros alimentícios (Critchley, 1991).

\section{Conclusão}

O botulismo é uma intoxicação alimentar causada por esporos do bacilo Clostridium botulinum que se desenvolve em ambientes anaeróbicos, geralmente em compostos orgânicos decompostos. Em cães, o alimento geralmente está contaminado com a neurotoxina do tipo C. O tratamento é de suporte e o prognóstico, geralmente, é favorável.

\section{Referências bibliográficas}

Barsanti, J. A. (2011). Infectious diseases of the dog and cat. In: C. E. Greene and W. B. Saunders (eds.) Botulism. p 416-423. Elsevier Health Sciences, Philadelphia, USA.

Bruchim, Y., Steinman, A., Markovitz, M., Baneth, G., Elad, D. \& Shpigel, N. Y. (2006). Toxicological, bacteriological and serological diagnosis of botulism in a dog. Veterinary Record, 158, 768-769.

Chrisman, C., Mariani, C., Platt, S.\& Clemmons, R. (2005). Neurologia para o clínico de pequenos animais. Editora Roca, São Paulo.

Coleman, E. S. (1998). Clostridial neurotoxins: tetanus and botulism. The Compendium on continuing education for the practicing veterinarian, 20, 1089-1097.

Critchley, E. M. R. (1991). A comparison of human and animal botulism: a review. 
Journal of the Royal Society of Medicine, 84, 295-298.

Devers, K. G. \& Nine, J. S. (2010). Autopsy findings in botulinum toxin poisoning. Journal of Forensic Sciences, 55, 1649-1651.

Doutre, M. P. (1983). Seconde observation de botulisme de type D chez le chien du Sénégal. Revue d'élevage et médecine vétérinaire des pays tropicaux, 36.

Farrow, B., Murrell, W., Revington, M., Stewart, B. \& Zuber, R. (1983). Type C botulism in young dogs. Australian Veterinary Journal, 60, 374-377.

Fernández, V. L. \& Bernardini, M. (2010). Neurologia em cães e gatos. Editora MedVet, São Paulo.

Ferreira, M. C. S., \& Domingues, R. M. C. P. (2008). Clostridium. In: L. R. Trabulsi \& F. Alterhum (eds.) Microbiologia. p 397-403. Ateneu, São Paulo.

Gregory, A. R., Ellis, T. M., Jubb, T. F., Nickels, R. J. \& Cousins, D. V. (1996). Use of enzyme-linked immunoassays for antibody to types $\mathrm{C}$ and $\mathrm{D}$ botulinum toxins for investigations of botulism in cattle. Australian Veterinary Journal, 73, 55-61.

Johnston, S. D., Kustritz, M. V. R. \& Olson, P. S. (2001). Canine and feline theriogenology. In: S. D. ohnston, M. V. Root Kustritz \& P. N. S. Olson (eds.) Canine and Feline Theriogenology. p 70-99. Saunders, Philadelphia.

Jubb, T. F., Ellis, T. M. \& Gregory. A. R. (1993). Diagnosis of botulism in cattle using ELISA to detect antibody to botulinum toxins. Australian Veterinary Journal, 70, 226-227.

Lamoureux, A., Pouzot-Nevoret, C. \& Escriou, C. (2015). A case of type B botulism in a pregnant bitch. Journal of Small Animal Practice, 56, 348-350.

Lorenz, M. D., \& Kornegay, J. N. (2006). Neurologia veterinária. Manole, Barueri.

Myllykoski, J., Lindström, M., Bekema, E., Pölönen, I. \& Korkeala, H. (2011). Fur animal botulism hazard due to feed. Research in Veterinary Science, 90, 412-418.

Nelson, R. W., \& Couto, C. G. (2015). Medicina interna de pequenos animais. Elsivier Editora, Amsterdan.
Quinn, P. J., Markey, B. K., Carter, M. E., Donnelly, W. J. \& Leonard, F. C. (2005). Microbiologia veterinária e doenças infecciosas. Artmed, Porto Alegre.

Rocke, T. E., Smith, S. R. \& Nashold, S. W. (1998). Preliminary evaluation of a simple in vitro test for the diagnosis of type $\mathrm{C}$ botulism in wild birds. Journal of Wildlife Diseases, 34, 744-751.

Rossetto, O., Megighian, A., Scorzeto, M. \& Montecucco, C. (2013). Botulinum neutoxins. Toxicon, 67, 31-36.

Sobel, J., Tucker, N., Sulka, A., McLaughlin, J. \& Maslanka, S. (2004). Foodborne botulism in the United States, 1990-2000. Emerging Infectious Diseases journal, 10, 1606-1611.

Tjalsma, E. J. (1990). 3 cases of Clostridium botulinum type $\mathrm{C}$ intoxication in the $\mathrm{dog}$. Tijdschrift voor diergeneeskunde, 115, 518521.

Tortora, G. J., Funke, B. R. \& Case, C. L. (2009). Microbiologia. Artmed Editora, Porto Alegre.

Uriarte, A., Thibaud, J.-L. \& Blot, S. (2010). Botulism in 2 urban dogs. The Canadian Veterinary Journal, 51, 1139-1142.

Wallace, V., \&McDowell, D. M. (1986). Botulism in a dog-First confirmed case in New Zealand. New Zealand Veterinary Journal, 34, 149-150.

Whitlock, R. H., \& Buckley, C. (1997). Botulism. The Veterinary clinics of North America. Equine practice, 13, 107-128.

Woudstra, C., Le, C., Souillard R., BayonAuboyer, M. H., Mermoud, I., Desoutter, D. \& Fach, P. (2016). New Insights into the genetic diversity of Clostridium botulinum Group III through extensive genome exploration. Frontiers in Microbiology, 7, 757.

\section{Article History:}

Received 26 June, 2016

Accepted 18 July, 2016

Available on line 15 Augusto, 2016

License information: This is an open-access article distributed under the terms of the Creative Commons Attribution License, which permits unrestricted use, distribution, and reproduction in any medium, provided the original work is properly cited. 